\title{
Formation of hydrogen blisters during the solution treatment for aluminum alloys
}

\author{
Daniel Diehl ${ }^{1 *}$ (1D \\ Eduardo Luis Schneider ${ }^{1}$ \\ Thomas Gabriel Rosauro Clarke ${ }^{1}$
}

\begin{abstract}
The solution treatment of aluminum alloys can be restricted by the presence of porosity defects caused by the moisture present in the process or by the hydrated front on the material surface. Hydrogen blisters cause deleterious effects on mechanical properties and surface finish. However, the formation of bubbles in solid aluminum is not caused only by the known reaction $2 \mathrm{Al}+3 \mathrm{H}_{2} \mathrm{O}=3 \mathrm{H}_{2}+\mathrm{Al}_{2} \mathrm{O}_{3}$, as it does not explain the interaction of the aluminum oxide layer with the formation mechanisms. In addition, the literature approaches show that there is more than one mechanism for the formation of these defects, but no work has made an association between them. Thus, the objective of this work is to carry out extensive research on the state of the art of hydrogen blister formation in aluminum alloys during the solubilization heat treatment. Contemplating different proposed mechanisms of bubble formation on the surface and structure, the analysis of this association of approaches indicated that the mechanisms depend on both permeability, where the hydrated oxide front creates passage for the formation of blister in the sublayer, as well as diffusion and hydrogen solubility in the microstructure.
\end{abstract}

Keywords: Aluminum alloys; Heat treatment; Hydrogen; Oxidation; Blister.

\section{Introduction}

Almost all metals contain small amounts of oxygen, hydrogen and nitrogen in their composition, which are often referred to as gases in metals [1,2], whether or not they exist as oxides, hydrides and nitrides [3-5]. The deleterious effects of hydrogen on mechanical properties of metals are well known and have been extensively studied [5-9].

Hydrogen is easily absorbed by reaction of aluminum with water, which comes from sources such as atmospheric moisture, flow of microscopic materials, wet casting tools or organic substances, thus supplying aluminum oxide and dissolved atomic hydrogen [10-12]. In addition, hydrogen absorption mechanisms in solution heat treatment start in surface reactions of aluminum with oxide layer [13-16], cathodic regions can favor hydrogen absorption reactions [17]. Despite this, hydrogen has a low solubility in molten aluminum and, in solid form, and at solution temperature, it has a solubility twenty times lower $[12,18]$.

The complexity of hydrogen blister formation in high temperature heat treatment processes for aluminum alloys is not well-formulated [12]. Figure 1 shows the characteristic defect caused by hydrogen blisters, this defect representing by Hu et al. [19] and MacKenzie [20].

Therefore, understanding the formation of hydrogen blister during heat treatment of aluminum, as well as mechanisms that act in formation of this defect, is essential for reducing production costs of $\mathrm{Al}$ alloys, increasing its quality and enhancing its potential mechanical performance. Thus, this work aims to survey and review literature about mechanisms that explain introduction of hydrogen in aluminum alloys during heat treatment operations. This work comprehends analysis in literature of heat treatments of aluminum alloys with temperature within $465{ }^{\circ} \mathrm{C}$ and $530{ }^{\circ} \mathrm{C}$.

\section{Hydrogen in high temperature solid aluminum alloys}

One of the characteristics of heat treatment of aluminum [21] is rapid formation of a thin layer of passive oxide of Al2O3 [22-24]. The hydrogen bubbles formed in the aluminum microstructure during heat treatment depend on many aspects, such as water vapor pressure [25], solubility [26,27], permeability, diffusivity [28] and activity $[28,29]$. Some of these aspects can be verified by mass spectrometric analyzer [11] or a thermal desorption spectroscopy system [30]. These factors influence the appearance and growth of blisters. The techniques for measuring hydrogen gas trapped inside micropores can be done using analytical methods such as electric energy loss spectroscopy (EELS) and ultraviolet absorption spectroscopy

\footnotetext{
${ }^{1}$ Programa de Pós-graduação em Engenharia de Minas, Metalúrgica e de Materiais, Laboratório de Metalúrgica Física, Universidade Federal do Rio Grande do Sul-UFRGS, Porto Alegre, RS, Brasil.

*Corresponding author: daniel.diehl90@gmail.com
} 

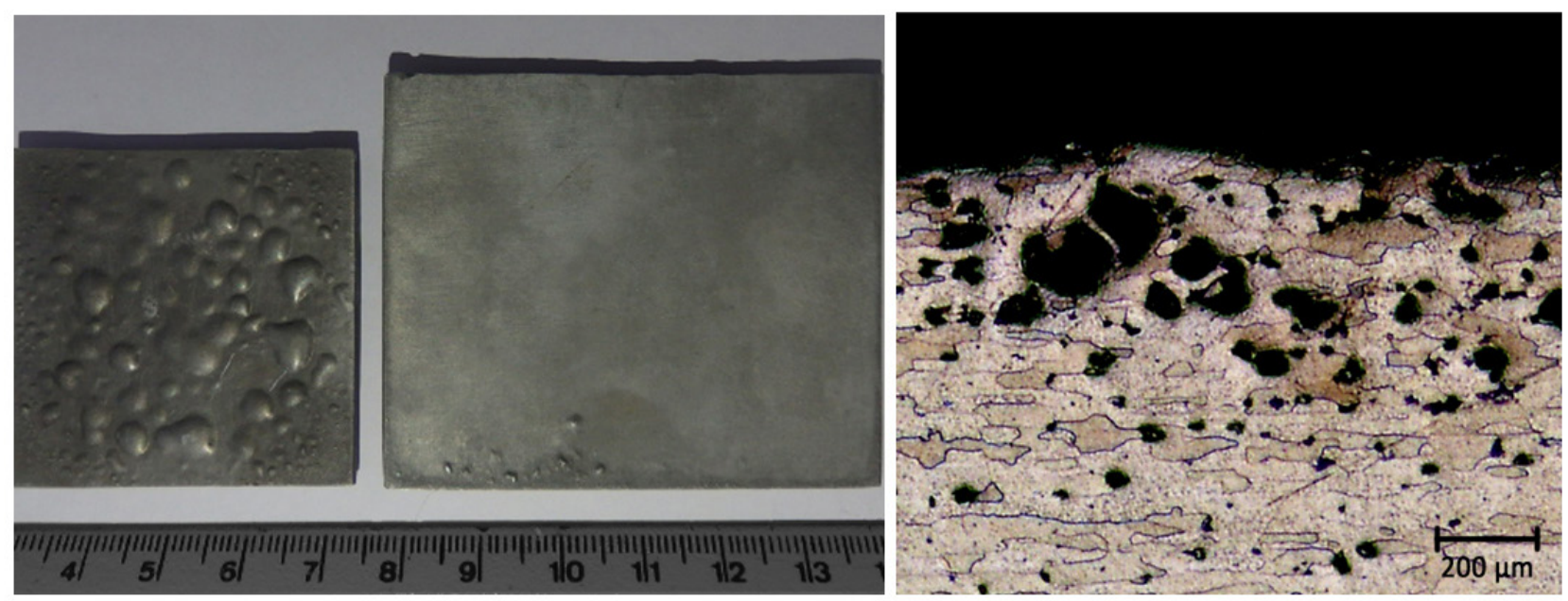

Figure 1. Typical morphology of porosities caused by hydrogen blisters formed during the heat treatment of aluminum alloys [19,20].

(UVAS), which identify blisters between 1 to $100 \mathrm{~nm}$ in size, as well as energy changes in hydrogen excitations. Huang HDS scattering (which is suitable for identifying blister of about $10 \mathrm{~nm}$ ) can be applied to visualize the deformation fields around pores.

\subsection{Permeability}

The permeability factor describes dependence of gas flow through metal and the gas pressure at the inlet end of metal membrane. In this sense, it follows that $\ddot{I}=D^{*} K_{S}$, the exponential relationship of the diffusion coefficients $\mathrm{D}$ and solubility $\mathrm{K}_{\mathrm{s}}$ with temperature explaining nature of exponential dependence on temperature permeability, that is, $\mathrm{D}=\mathrm{D} 0 \exp (-\mathrm{EDiff} / \mathrm{R} * \mathrm{~T})$ e $\mathrm{Ks}=\mathrm{KS} 0 \exp \left(-\mathrm{E}_{\mathrm{S}} / \mathrm{R}_{*} \mathrm{~T}\right)$.

The permeability factor, as well as differences between melting and solubility coefficients, are values determined exclusively for a specific gas. The diffusion of gas through the metal is limiting element of mass transfer process. That is, permeability is related to diffusivity and hydrogen absorption [31] and time dependence on hydrogen permeation is controlled by its mass diffusion. The effect of oxide layers that inherently cover surface of aluminum samples is insignificant during the heat treatment [32]. On the other hand, for Steward [31], the effect of surface condition of aluminum, such as its roughness and its contaminating materials, affects permeability of hydrogen, in analysis of Ulanovskiy data [1], permeability varies between $-6.25 \mathrm{e}-8.75 \mathrm{~cm}^{3}(\mathrm{NTP}) . \mathrm{cm} / \mathrm{cm}^{2} . \sec (\mathrm{mmHg})^{1 / 2}$.

\subsection{Diffusivity}

For diffusivity, in aluminum alloy at temperatures in range of $465{ }^{\circ} \mathrm{C}$ to $530{ }^{\circ} \mathrm{C}$ there is a discrepancy between analyzes of authors Ulanovskiv [1] and Anyalebechi [32], the former author has found diffusivity between -3.25 to

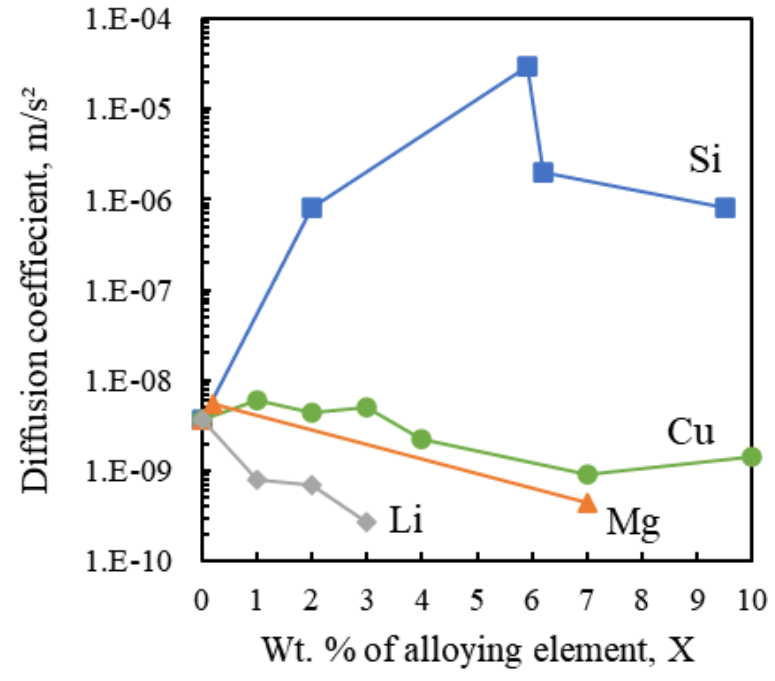

Figure 2. Effect of alloying elements on hydrogen diffusion coefficient in aluminum alloys at $673 \mathrm{~K}[32]$.

$-6.9 \mathrm{lgD}$, and later found a diffusivity between -7 to 9.5 for temperature range mentioned above. The behavior of diffusivity as a function of variation of content of some elements in aluminum alloy is shown in Figure 2. However, studies cover a wide range of conditions, including the effects of temperature, oxide, grain size, aluminum sample purity, sample surface condition and fabricated sample shape [32]. Furthermore, the correlation between distribution of slip and hydrogen sensitivity suggests possibility that moving displacement facilitates transportation of hydrogen material.

\subsection{Solubility and activity}

The low solubility of hydrogen in aluminum during its heat treatment makes it particularly difficult to quantify 
the hydrogen concentrations in lattice [18] which, according to Steward, causes a great dispersion in results found in literature on this topic. Ulanovskiy [1] analyzed some of these data, which also showed discrepancies in hydrogen diffusion coefficients and activation energy values, which can be caused by differences in materials used, in addition to the fact that 'surface' hydrogen is not taken into account and that is captured by other mechanisms.

Anyalebechi [33] shows at what heat treatment temperature aluminum can adsorb free hydrogen $\mathrm{H}+$ from $\mathrm{H} 2$ dissociation. Hydrogen solubility and activity are significantly influenced by chemical composition of alloy $[33,34]$. In other works $[35,36]$ it is also shown that the microstructure affects permeability of aluminum alloys. The influence of solubility and hydrogen activity as a function of the content of some elements of alloy present in aluminum at a solution temperature of $500{ }^{\circ} \mathrm{C}$ is shown in Figure 3 .

The work by He et al. [34] shows that for an alloy Al-Cu-Ga-In-Sn increasing the copper content to up to $8 \%$ decreases the hydrogen solubility, while its production of blisters has become more intensified with higher concentrations of copper [34], as also shown in Figure 2 [32]. This increase is justified by increase in hydrogen activity in alloy with higher copper content. The activation energy values of hydrogen solubility in aluminum found by other authors [35,37-39] are relatively close, being between 30 and $80 \mathrm{~kJ} \cdot \mathrm{mol}^{-1}$.

\subsection{Blister formation mechanism through oxide film}

For the formation of hydrogen blisters, aluminum corrosion must occur $[40,41]$. This requires the presence of water and, thus, the metal to oxidize $[42,43]$. The use of the relationship between aluminum oxide and water can be made from possible electrochemical situations, analyzing the cathodic and anodic

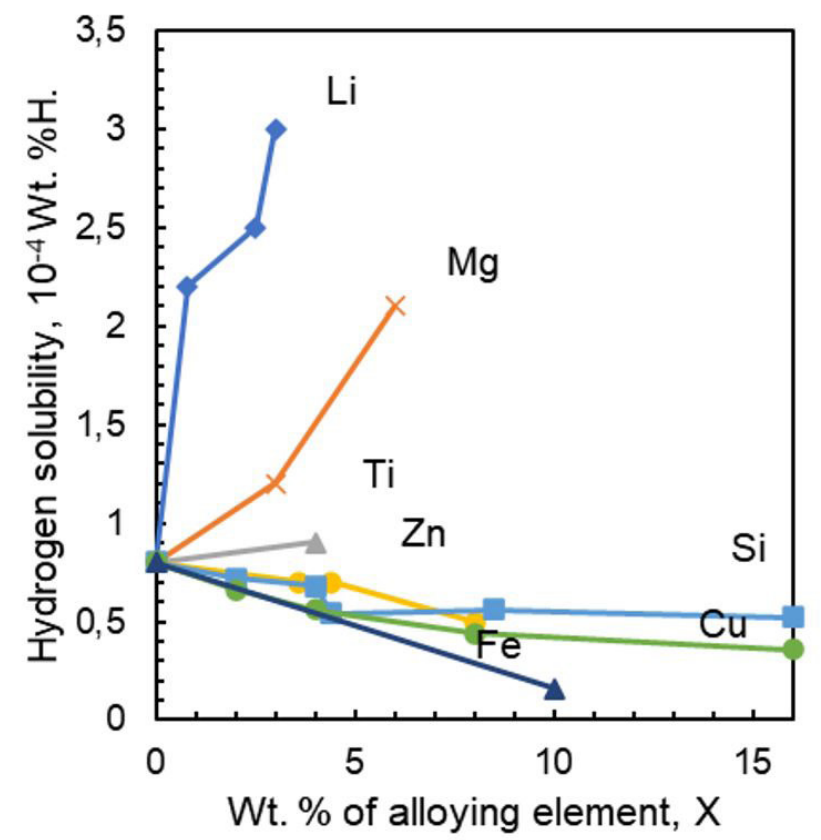

potentials [44]. The oxide film is not a barrier to hydrogen permeation [30]. The heat treatment steps of solubilization influence the reactivity of the $\mathrm{Al}_{2} \mathrm{O}_{3}$ layer with atmospheric $\mathrm{H}_{2} \mathrm{O}$ [45]. According to previous work [26,38,46], the chemical reactions that explain formation of hydrogen gas from atmospheric $\mathrm{H}_{2} \mathrm{O}$ are those shown in Equations 1, 2 and 3, which concern the mechanism of formation of subsurface hydrogen blisters.

$$
\begin{aligned}
& \mathrm{Al}_{2} \mathrm{O}_{3}+3 \mathrm{H}_{2} \mathrm{O} \rightarrow 2 \mathrm{Al}(\mathrm{OH})_{3} \\
& \mathrm{Al}(\mathrm{OH})_{3}+\mathrm{Al} \rightarrow \mathrm{Al}_{2} \mathrm{O}_{3}+\mathrm{H}_{2} \uparrow \\
& 2 \mathrm{Al}+6 \mathrm{H}_{2} \mathrm{O} \rightarrow 2 \mathrm{Al}(\mathrm{OH})_{3}+3 \mathrm{H}_{2} \uparrow
\end{aligned}
$$

In Figure $4 \mathrm{a}$ it is shown that the compound $\mathrm{Al}_{2} \mathrm{O}_{3}$, which constitutes an amorphous oxide film called alumina $\left(\alpha-\mathrm{Al}_{2} \mathrm{O}_{3}\right)$, reacts with water, producing the compound $\mathrm{Al}(\mathrm{OH})_{3}$, which is a hydrated oxide front in its recrystallized [45]. Thus, the surface alumina oxide can be transformed into a hydrated oxide by absorbing moisture [47], as shown in Equation 1. The solubilization treatment range between $450{ }^{\circ} \mathrm{C}$ and $500{ }^{\circ} \mathrm{C}$ without atmospheric control favors the transformation of amorphous aluminum oxide film into hydrated oxide on the surface due to its activity $[42,47]$.

In this temperature range, the formation of gibbsite and bayerite is also promoted, as shown in Figure 5, which shows Gibbs free energy graph by temperature of aluminum alloy. Then, Figure $4 \mathrm{~b}$ shows that the hydrated oxide front $\mathrm{Al}(\mathrm{OH})_{3}$ in contact with Al produces subsurface $\mathrm{H}_{2}$, as Equation 2. The hydrated oxide film formed on sample surface thus creates additional resistance to transfer of formed gas, causing it to form blisters.

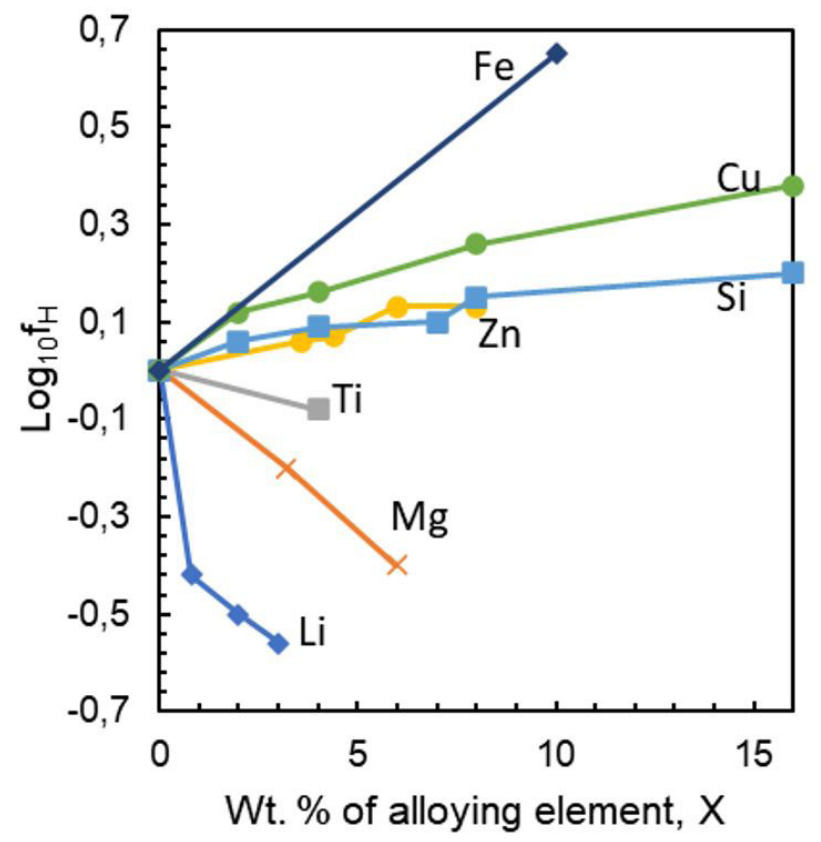

Figure 3. Effect of the content of alloying elements on the solubility and activity of hydrogen in Al [33]. 

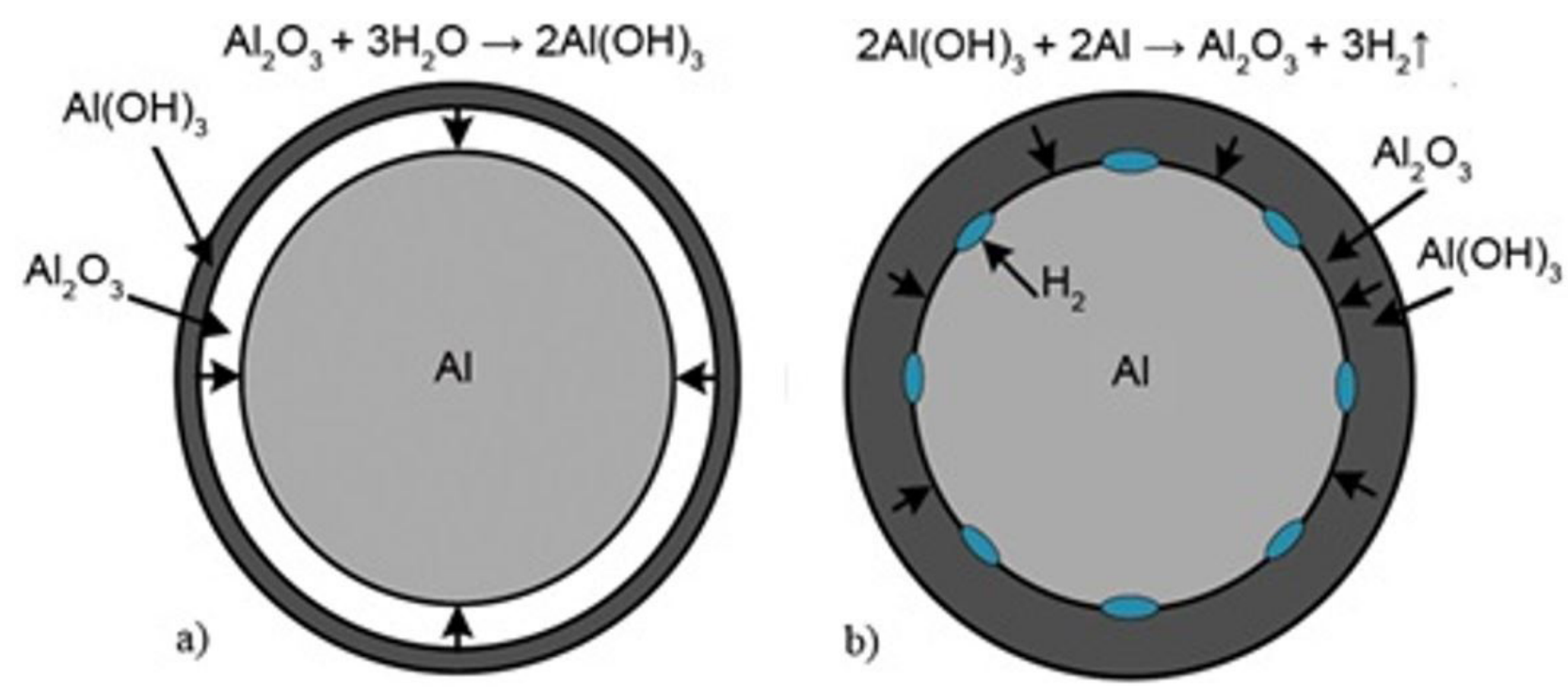

Figure 4. Formation and advancement of hydrated front of $\mathrm{Al}(\mathrm{OH}) 3$ in (a), Formation of hydrogen blisters at interface $\mathrm{Al}(\mathrm{OH}) 3$ and $\mathrm{Al}$ in (b)

Mackenzie [20] charge hydrogen blisters formed during heat treatment by transition to $\mathrm{Al} 2 \mathrm{O} 3$ hydration $\mathrm{AlOOH}$ (boehmite) shows in Figure 6a, although this is not formed in solution temperature, although heating does not prevent this compound from being formed [48] shows that the formation of blisters that transform surface oxide into boehmite occurs at temperatures lower than that of solution. In Figure 6b, the oxide transition creates a hydrated front which is the precursor to formation of hydrogen blisters in aluminum surface sublayer, as shown in Equations 4, 5 and 6.

$$
\mathrm{Al}_{2} \mathrm{O}_{3}+\mathrm{H}_{2} \mathrm{O} \rightarrow 2 \mathrm{AlOOH}
$$

$\mathrm{Al}+\mathrm{AlOOH} \rightarrow \mathrm{H}_{2}+\mathrm{Al}_{2} \mathrm{O}_{3}$

$$
\mathrm{Al}+2 \mathrm{H}_{2} \mathrm{O} \rightarrow \mathrm{AlOOH}+3 \mathrm{H}_{\text {interticial }}
$$

It is necessary for water to contact $\mathrm{Al}$ directly or through oxide layer to reaction of Equations 3 and 6 to occur. The authors $[46,47]$ mention two ways to explain contact of aluminum with water. One way explains that water may have permeated the surface layer of hydrated oxide and other way explain that it may have been formed within microstructure by other mechanisms [40]. The first is explained by micro cavities [8] in oxide layer, as shown in Figure 6c. Li [8] estimates that such micro cavities evolve rapidly to cavities when alloy is exposed to temperatures above $150^{\circ} \mathrm{C}$.

\subsection{Nucleation and growth of microporosities}

Toda et al. [49] show that heterogeneous nucleation sites are necessary for hydrogen to form micropores and thus, if these sites are not present, microporosity formation

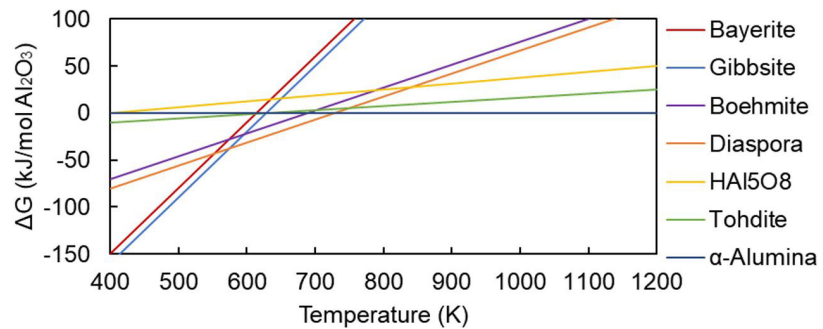

Figure 5. Gibbs free energy of aluminum hydroxide compared to aluminum oxide as a function of temperature [42].

is effectively suppressed. The analyzes of these authors show that a pure aluminum did not form micropores at heat treatment temperature of $550{ }^{\circ} \mathrm{C}$ in a time of $90 \mathrm{~h}$. However, the hydrogen was trapped in its microstructure. Su et al. [14] and Toda et al. [49] identified that hydrogen gets stuck in vacancies, making it impossible to move vacancies. For a sample of Al-Zn-Mg alloy, Su et al. [15] indicated distribution of hydrogen in favorable regions and its atomic concentration in regions, as shown in Figure 7.

The work by Su et al. [14] indicates that nucleated hydrogen micropores in particles show premature growth when under loading, revealing such research also that between 7 to $28 \%$ of fractures originate from hydrogen micropores. Often, in Al-Mg alloys, about half of hydrogen atoms are trapped in such micropores. The supersaturated hydrogen atoms in aluminum alloys migrate to places such as interstitial positions, vacancies, disagreements, solute atoms, precipitates, intermetallic particles and high-angle grain outlines. After the nucleation of a hydrogen micropore in aluminum alloy it becomes one of the preferred places for its growth in aluminum alloys.

According to Zhang et al. [50] hydrogen micropores are formed from hydrogen vacancy groups. Other studies $[11,14]$ however, show that hydrogen micropores are heterogeneously 

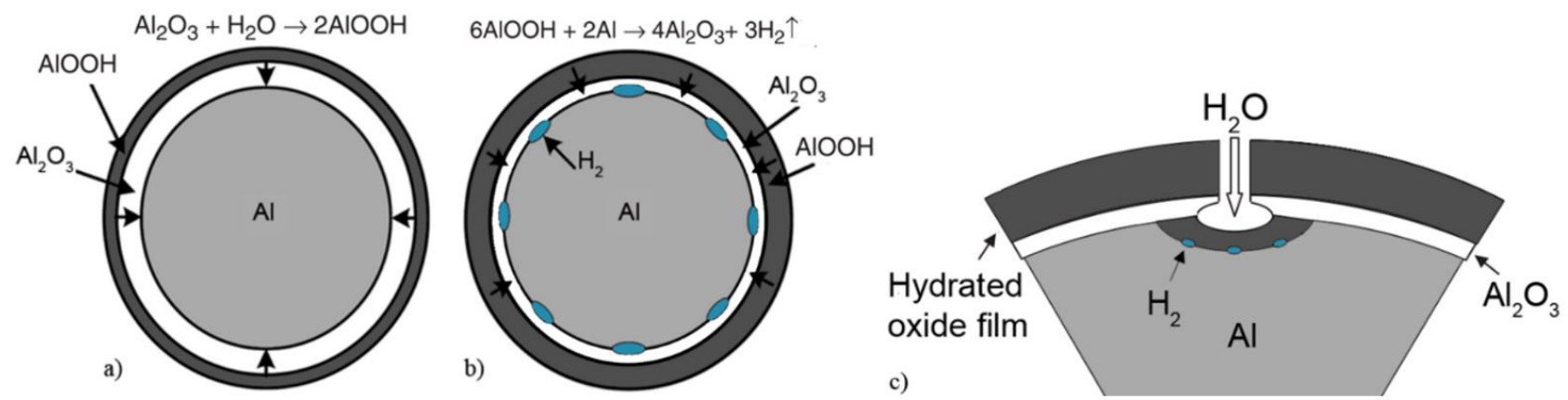

Figure 6. (a) formation and advancement of hydrated $\mathrm{AlOOH}$ front; (b) formation of blisters at $\mathrm{Al}$ interface [47] and (c) representation that points out that reaction of metal $\mathrm{Al}$ with water continues after the breakdown of hydrated oxide film [46].

initiated, generally in regions of intermetallic particles in aluminum alloys containing zinc, magnesium and copper.

The displacement of $\mathrm{H}$ from an octahedral void in aluminum grid to a vacancy is accompanied by an energy gain of $1.23 \mathrm{eV}$. Vacancies are stable regions for the formation of $\mathrm{H}_{2}$, as well as contours and disagreements. The total amount of dissolved hydrogen is determined by pressure of hydrogen and high pressures by its volatility $[8,14,15,41]$. Hydrogen ions will be present in a significant amount at interstitial lattice locations, grain boundaries and vacancies $[21,24]$.

Another mechanism for formation of micropores in internal regions is the formation of hydrides with elements present in aluminum alloys, such as $\mathrm{Mg}, \mathrm{Li}$ and $\mathrm{Ti}$, which due to their high affinity increase solubility of hydrogen $[1,39]$. Despite this, newly formed hydrides are easily displaced to regions of high free energy in microstructure, such as grain outlines and discrepancies, places in which release of hydrogen favors formation of $\mathrm{H}_{2}$ [26]. Part of origin of the blisters may be related to these hydrides $[47,51,52,53]$. For example, the segregation of magnesium is responsible for part of hydrogen concentration inside the microstructure, given permeation of this metal to grain boundaries, but it is only when a certain level of precipitation occurs in grain boundaries that cracks, due to hydrogen embrittlement, can be nucleated and microstructure becomes susceptible to stress corrosion and fatigue corrosion [54]. It may be that formation of hydrides occurs selectively in incoherent interfaces of precipitates and in contours of grains, thus facilitating nucleation of cracks.

In recent years, images obtained from microtomography by X-ray analysis have been used to observe sites of hydrogen nucleation in aluminum alloys that have undergone thermal treatment of solubilization. Suppose observed micropores are thermal equilibrium, where surface tension $\gamma$ is balanced by an opposite gas pressure within a micropore P [49], follows that $\mathrm{P}=4 \gamma / \mathrm{d}_{\emptyset \text { poro }}$, where $\mathrm{d}$ is the radius of micropore. Two possible growth mechanisms under this thermal equilibrium would be the migration and coalescence of micropores. For the first mechanism to work, micropores must migrate via atom transport through surface diffusion, vacancy volume diffusion, or vapor transport [49]. The focus of this study is limited to treatment solution time, which in turn is based on literature and industry recommendations, and is generally

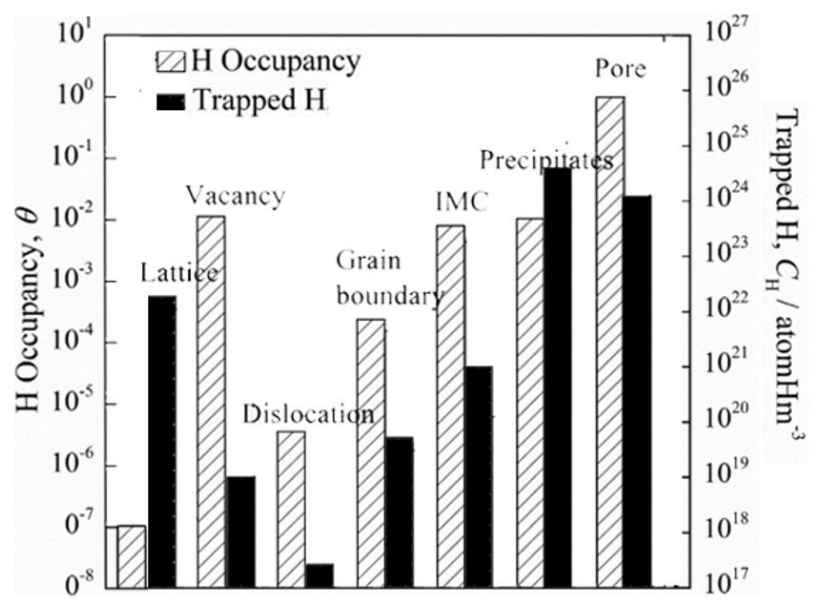

Figure 7. Comparison between the hydrogen distribution in defect regions and the ratio of the hydrogen content captured in specific hydrogen capture locations [15].

stipulated within $3 \mathrm{~h}[20]$. Therefore, the formation of blister until this time interval is considered in this study.

Through the analysis of microtomography in an aluminum alloy at a temperature of $500{ }^{\circ} \mathrm{C}$, Sue et al. [14] showed that intermetallic $\mathrm{Mg}_{2} \mathrm{Si}$ (green) and second phase particles (blue) form nucleation sites, and pore A growth, shows Figure 8a. When blister formation mechanisms are activated, blister concentration increases rapidly, Figure $8 \mathrm{~b}$ shows increase in blister concentration in $0.5 \mathrm{~h}$ of treatment. However, in Figure 8c at $1.25 \mathrm{~h}$, low growth and nucleation of hydrogen blisters were observed. The average diameter of hydrogen micropores increases with increasing time of exposure to heat treatment. In long times, such as $7.16 \mathrm{~h}$ (Figure 8d), intermetallic particles dissolve and micropores coalesce soon. Sue et al. [14] also observed that growth in spherical particles is greater than in angular particles.

Toda et al. [49] analyzed four samples of aluminum alloys $\mathrm{LH}, \mathrm{MH}, \mathrm{HH}$ and $5 \mathrm{~N}-\mathrm{Al}(99.99 \% \mathrm{Al})$ submitted to times longer than indicated for their heat treatment and observed that rapid growth of blisters occurs after $5 \mathrm{~h}$, as shown Figure 8.

This growth, however, can be activated within time specified for the solution treatment if conditions are favorable. The decrease in hydrogen diffusivity and the increase in its 

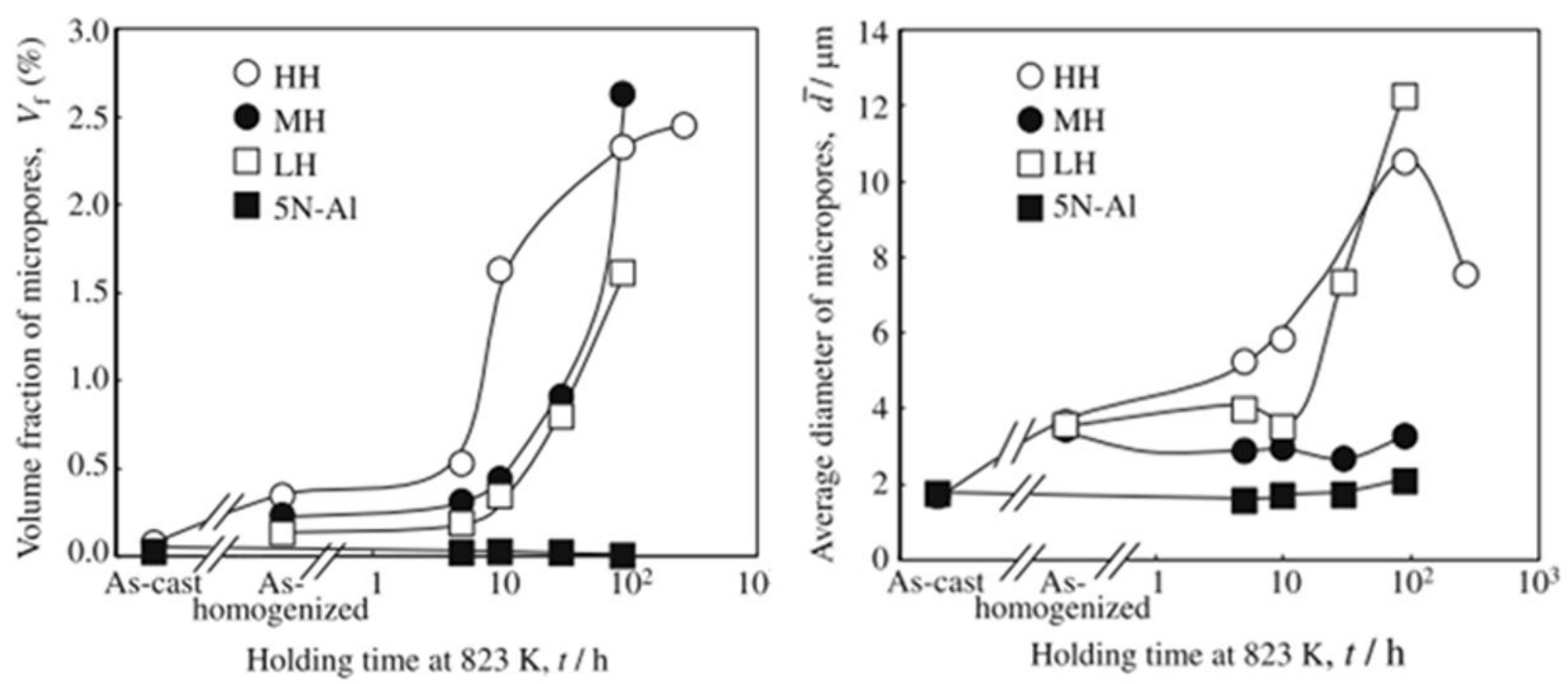

Figure 8. variation of the heat treatment time at the temperature of $823 \mathrm{~K}$ shows the behavior of the volume fraction of micropores in (a) and the average diameter of the micropores in (b).

solubility are attributable to presence of molecular hydrogen in pores $[10,49]$. It can be concluded that we can control the formation of hydrogen bubbles during heat treatment at high temperature if we know the mechanisms of these formations, as well as external factors or how the condition of the material favors the formation

\section{Conclusion}

Many authors have addressed the mechanisms of hydrogen blister formation in aluminum alloys. In this article it was possible to analyze blister formation models on the surface and structure of aluminum alloys. It was indicated that, at high temperatures during thermal treatment of solubilization, the reaction of hydrogen formation is not a simple and direct reaction of $2 \mathrm{Al}+3 \mathrm{H}_{2} \mathrm{O}=3 \mathrm{H}_{2}+\mathrm{Al} 2 \mathrm{O} 3$, the mechanisms depend both on permeability, where hydrated oxide front creates passage for formation of blisters in sublayer, and on diffusion and solubility of hydrogen in microstructure. That is, as microporosity is growing, it affects diffusivity and solubility and vice versa. The formation of microporosities that originate hydrogen blisters, however, can be limited by absence of intermetallic. In pure aluminum there was no blister growth, and it was observed that vacancies were equipped with hydrogen, which limited its displacement.

\section{References}

1 Ulanovskiy I. Hydrogen diffusion and porosity formation in aluminum. Moscou: MIS\&S; 2015 [cited 2020 mar 14]. Available at: http://eanw.info/enzilkopedia/ulanovskii/ulanovsky-hydrogen.pdf

2 Alefeld G, Völkl J. Hydrogen in metals I - Basic properties. Berlin: Springer-Verlag; 1978 [cited 2020 feb 3 ]. Available at: https://link.springer.com/book/10.1007/3-540-08705-2.

3 Bochkaryova A, Li Y, Barannikova S, Zuev L. The effect of hydrogen embrittlement on the mechanical properties of aluminum alloys. IOP Conference Series Materials Science and Engineering. 2015;71(1):12-57. https://doi. org/10.1088/1757-899X/71/1/012057.

4 Preez S, Bessarabov D. Hydrogen generation of mechanochemically activated Al-Bi-In composites. International Journal of Hydrogen Energy. 2017;42(26):16589-16602. https://doi.org/10.1016/j.ijhydene.2017.05.211.

5 Bochkaryova AV, Li YV, Barannikova SA, Zuev LB. The effect of hydrogen embrittlement on the mechanical properties of aluminum alloy. IOP Conference Series Materials Science and Engineering. 2015;71:012057. https:// doi.org/10.1088/1757-899X/71/1/012057.

6 Krishnan M, Raja V. Role of temper conditions on the hydrogen embrittlement behavior of AA 7010. Corrosion Science. 2019;152:211-217. https://doi.org/10.1016/j.corsci.2019.03.004. 
7 Shimizu K, Toda H, Fujihara H, Hirayama K, Uesugi K, Takeuchi A. Hydrogen partitioning behavior and related hydrogen embrittlement in Al-Zn-Mg alloys. Engineering Fracture Mechanics. 2019;216:106503. https://doi. org/10.1016/j.engfracmech.2019.106503.

8 Li M, Xie D, Ma E, Li J, Zhang X, Shan Z. Effect of hydrogen on the integrity of aluminium-oxide interface at elevated temperatures. Nature Communations. 2017 [cited 2020 mar 30];8:1-7. Available at: https://www.nature. com/articles/ncomms14564.

9 Wang L, Yan H, Teng J, Liu X, Wang X, Su Y, et al. Effect of hydrogen on interfacial reaction between Ti-6Al-4V alloy melt and graphite mold. Journal of Materials Research and Technology. 2020;9(3):2623-2634. https://doi. org/10.1016/j.jmrt.2020.02.071.

10 Alba-Baena N, Eskin D. Kinetics of ultrasonic degassing of aluminum alloys. In: Sadler B, editor. Light metals 2013: the minerals, metals \& materials series. Berlim: Springer Cham; 2016. p. 957-962. https://doi. org/10.1007/978-3-319-65136-1_162.

11 Yamabe J, Awane T, Murakami Y. Hydrogen trapped at intermetallic particles in aluminum alloy 6061-T6 exposed to high-pressure hydrogen gas and the reason for high resistance against hydrogen embrittlement. International Journal of Hydrogen Energy. 2017;42(38):24560-24568. https://doi.org/10.1016/j.ijhydene.2017.08.035.

12 Tiryakioğlu M. The effect of hydrogen on pore formation in aluminum alloy castings: myth versus reality. Metals. 2020;10(3):368. https://doi.org/10.3390/met10030368.

13 Kudinova N, Polyanskiy V, Polyanskiy A, Yakovlev Y. Determining the bound energies of dissolved hydrogen on the basis of a multichannel diffusion model in a solid. St. Petersburg Polytechnical University Journal: Physics and Mathematics. 2015;1(4):347-355. https://doi.org/10.1016/j.spjpm.2016.02.003.

14 Su H, Bhuiyan S, Toda H, Uesugi K, Takeuchi A, Watanabe Y. Influence of intermetallic particles on the initiation and growth behavior of hydrogen micropores during high-temperature exposure in $\mathrm{Al}-\mathrm{Zn}-\mathrm{Mg}-\mathrm{Cu}$ aluminum alloys. Scripta Materialia. 2017;135:19-23. https://doi.org/10.1016/j.scriptamat.2017.03.020.

$15 \mathrm{Su} \mathrm{H}$, Toda H, Shimizu K, Uesugi K, Takeuchi A, Watanabe, Y. Assessment of hydrogen embrittlement via imagebased techniques in Al-Zn-Mg-Cu aluminum alloys. Acta Materialia. 2019;176:96-108. https://doi.org/10.1016/j. actamat.2019.06.056.

16 Chung C, Tsai C, Hsu C, Kuo E, Chen Y, Chung I. Impurity and temperature enhanced growth behaviour of anodic aluminium oxide from AA5052 Al-Mg alloy using hybrid pulse anodization at room temperature. Corrosion Science. 2017;125:40-47. https://doi.org/10.1016/j.corsci.2017.05.027.

17 Polyanskii V. Role of hydrogen embrittlement in the corrosion cracking of aluminum alloys. Materials Science. 1986; 21:301-309. https://doi.org/10.1007/BF00726550.

18 Talbot D, Anyalebechi P. Solubility of hydrogen in liquid aluminium. Materials Science and Technology. 1988;4(1):1-4. https://doi.org/10.1179/mst.1988.4.1.1.

$19 \mathrm{Hu}$ X, Zhu Q, Midson S, Atkinson H, Dong H, Zhang F et al. Blistering in semi-solid die casting of aluminium alloys and its avoidance. Acta Materialia. 2017;124:446-455. https://doi.org/10.1016/j.actamat.2016.11.032.

20 MacKenzie D. Metallurgy of heat treatable aluminum alloys. In: Anderson K, Weritz J, Kaufman J, editors. Aluminum science and technology. Vol. 2A. USA: ASM International; 2018. p. 411-437. https://doi.org/10.31399/ asm.hb.v02a.a0006509.

21 Diehl D, Köhler C, Schneider EL, Clarke TGR. Eddy current at high temperatures for in-situ control of heat treatment precipitation in hardening aluminum alloys. 2020. IEEE Sensors Journal. https://doi.org/10.1109/ JSEN.2020.3008629.

22 Wang H, Leung D, Leung M, Ni M. A review on hydrogen production using aluminum and aluminum alloys. Renewable and Sustainable Energy Reviews. 2009;13(4):845-853. https://doi.org/10.1016/j.rser.2008.02.009.

23 Alviani V, Setiani P, Uno M, Oba M, Hirano N, Watanabe N et al. Mechanisms and possible applications of the $\mathrm{Al}-\mathrm{H} 2 \mathrm{O}$ reaction under extreme $\mathrm{pH}$ and low hydrothermal temperatures. International Journal of Hydrogen Energy. 2019;44(57):29903-29921. https://doi.org/10.1016/j.ijhydene.2019.09.152.

24 Francisco U, Larrosa N, Peel M. Hydrogen environmentally assisted cracking during static loading of AA7075 and AA7449. Materials Science and Engineering: A. 2020;772:138662. https://doi.org/10.1016/j.msea.2019.138662.

25 Burns J, Bush R, Ai J, Jones J, Lee Y, Gangloff R. Effect of water vapor pressure on fatigue crack growth in Al-Zn$\mathrm{Cu}-\mathrm{Mg}$ over wide-range stress intensity factor loading. Engineering Fracture Mechanics. 2015;137:34-55. https:// doi.org/10.1016/j.engfracmech.2014.11.009. 
26 Ta N, Zhang L, Li Q, Lu Z, Lin Y. High-temperature oxidation of pure Al: kinetic modeling supported by experimental characterization. Corrosion Science. 2018;139:355-369. https://doi.org/10.1016/j.corsci.2018.05.013.

27 Corrigall J, St Louis C, Coleman C, McRae G. A chemical potential probe to determine the solubility of hydrogen in metals: an example with Copper. Journal of Phase Equilibria and Diffusion. 2020;41:27-34. https://doi.org/10.1007/ s11669-019-00776-2.

28 Nguyen D, Vo D. Comprehensive finite element modeling for pulsed magnet design using COMSOL and Java. IEEE Transactions on Applied Superconductivity. 2020;30(4):1-5. https://doi.org/10.1109/TASC.2020.2971935.

29 Hardwick D, Taheri M, Thompson A, Bernstein I. Hydrogen embrittlement in a 2000-series aluminum alloy. Metallurgical Transactions A. 1982;13:235-239. https://doi.org/10.1007/BF02643313.

30 Young G, Scully J. The diffusion and trapping of hydrogen in high purity aluminum. Acta Materialia. 1998;46(18):6337-6349. https://doi.org/10.1016/S1359-6454(98)00333-4.

31 Steward S. Review of hydrogen isotope permeability through materials. Califórnia: Lawrence Livermore National Laboratory; 1983. p. 1-28. https://doi.org/10.2172/5277693.

32 Anyalebechi PN. Critical review of reported values of hydrogen diffusion in solid and liquid aluminum and its alloys. TMS Light Metals. 2003;857-872.

33 Anyalebechi P. Analysis of the effects of alloying elements on hydrogen solubility in liquid aluminum alloys. Scripta Metallurgica et Materialia. 1995;33(8):1209-1216. https://doi.org/10.1016/0956-716X(95)00373-4.

34 He T, Chen W, Wang W, Ren F, Stock H. Effect of different Cu contents on the microstructure and hydrogen production of Al-Cu-Ga-In-Sn alloys for dissolvable materials. Journal of Alloys and Compounds. 2020;821:153489. https://doi.org/10.1016/j.jallcom.2019.153489.

35 Marchi C, Somerday B, Robinson S. Permeability, solubility and diffusivity of hydrogen isotopes in stainless steels at high gas pressures. International Journal of Hydrogen Energy. 2007;32(1):100-116. https://doi.org/10.1016/j. ijhydene.2006.05.008.

36 Rudomilova D, Prošek T, Salvetr P, Knaislová A, Novák P, Kodým R, et al. The effect of microstructure on hydrogen permeability of high strength steels. Mater and Corros. 2019:1-9. https://doi.org/10.1002/ maco.201911357.

37 Jena P, Satterthwaite C. Eletronic structure and properties of hydrogen in metals. USA: Springer; 1983. https://doi. org/10.1007/978-1-4684-7630-9.

38 Nie H, Zhang S, Schoenitz M, Dreizin E. Reaction interface between aluminum and water. International Journal of Hydrogen Energy. 2013;38(26):11222-11232. https://doi.org/10.1016/j.ijhydene.2013.06.097.

39 Wang W, Chen W, Zhao X, Chen D, Yang K. Effect of composition on the reactivity of Al-rich alloys with water. International Journal of Hydrogen Energy. 2012;37(24):18672-18678. https://doi.org/10.1016/j. ijhydene.2012.09.164.

40 Vargel C. Corrosion of aluminium. USA: Elsevier; 2004. 626 p.

41 Zaffaroni G, Gudla V, Din R, Ambat R. Characterization of blisters on powder coated aluminium AA5006 architectural profiles. Engineering Failure Analysis. 2019;103:347-360. https://doi.org/10.1016/j. engfailanal.2019.04.039.

42 Digne M, Sautet P, Raybaud P, Toulhoat H, Artacho E. Structure and stability of aluminum hydroxides: a theoretical study. Journal of Physical Chemistry B. 2002;106(20):5155-5162. https://doi.org/10.1021/jp014182a.

43 Mozetic H, Fonseca E, Schneider EL, Kindlein W Jr, Schaeffer L. The use of magnetic field annealing on nodular cast iron for speaker cores. IOS Press. 2011:51-65. http://dx.doi.org/10.3233/JAE-2011-1395.

44 Zhao Q, Zhao J, Cheng X, Huang Y, Lu L, Li X. Galvanic corrosion of the anodized 7050 aluminum alloy coupled with the low hydrogen embrittlement CdTi plated $300 \mathrm{M}$ steel in an industrial-marine atmospheric environment. Surface and Coatings Technology. 2020;382:125171. http://dx.doi.org/10.1016/j.surfcoat.2019.125171.

45 Beck A, Heine M, Caule E, Pryor M. The kinetics of the oxidation of Al in oxygen at high temperature. Corrosion Science. 1967;7(1):1-22. http://dx.doi.org/10.1016/S0010-938X(67)80066-0.

46 Wang Y, Xu K, Li L. Inhibition of the reaction between aluminium dust and water based on the HIM. RSC Advances. 2017;7:33327-33334. http://dx.doi.org/10.1039/c7ra04787h.

47 Teng H, Lee T, Chen Y, Wang H, Cao G. Effect of $\mathrm{Al}(\mathrm{OH}) 3$ on the hydrogen generation of aluminum-water system. Journal of Power Sources. 2012;219:16-21. http://dx.doi.org/10.1016/j.jpowsour.2012.06.077. 
48 Deng Z, Ferreira J, Tanaka Y, Ye J. Physicochemical mechanism for the continuous reaction of $\gamma$-Al2O3-modified aluminum powder with water. Journal of the American Ceramic Society. 2007;90(5):1521-1526. http://dx.doi. org/10.1111/j.1551-2916.2007.01546.x.

49 Toda H, Hidaka T, Kobayashi M, Uesugi K, Takeuchi A, Horikawa K. Growth behavior of hydrogen micropores in aluminum alloys during high-temperature exposure. Acta Materialia. 2009;57(7):2277-2290. http://dx.doi. org/10.1016/j.actamat.2009.01.026.

50 Zhang P, Li Z, Liu B, Ding W. Effect of chemical compositions on tensile behaviors of high pressure die-casting alloys Al-10Si-yCu-xMn-zFe. Materials Science and Engineering A. 2016;661:198-210. http://dx.doi.org/10.1016/j. msea.2016.03.032.

51 Shen L, Chen H, Che X, Xu L. Hydrogen embrittlement of the 7B05-T5 aluminum alloy for high-speed trains. Materials and Corrosion. 2020;71(1):70-76. https://doi.org/10.1002/maco.201910975.

52 Anson J, Gruzleski JT. The quantitative discrimination between shrinkage and gas microporosity in cast aluminum alloys using spatial data analysis. Materials Characterization. 1999;43(5):319-335. http://dx.doi.org/10.1016/S10445803(99)00059-5.

53 Sigworth G, Engh T. Chemical and kinetic factors related to hydrogen removal from aluminum. Metallurgical Transactions B. 1982;3:447-460. https://doi.org/10.1007/BF02667761.

54 Kumar S, Namboodhiri T. Precipitation hardening and hydrogen embrittlement of aluminum alloy AA7020. Bulletin of Materials Science. 2011;34(2):311-321. http://dx.doi.org/10.1007/s12034-011-0066-8.

Received: 18 Aug. 2020

Accepted: 7 Jan. 2021 